Max-Planck-Institut für demografische Forschung

Max Planck Institute for Demographic Research

Konrad-Zuse-Strasse 1 - D-18057 Rostock · GERMANY

Tel +49 (0) 3812081 - 0; Fax +49 (0) 3812081 - 202;

http://www.demogr.mpg.de

MPIDR WORKING PAPER WP 2006-051

DECEMBER 2006

\title{
Does cohabitation prior to marriage raise the risk of marital dissolution and does this effect vary geographically?
}

Paul J. Boyle

Hill Kulu (kulu@ demogr.mpg.de)

This working paper has been approved for release by: Gerda Ruth Neyer (neyer@ demogr.mpg.de) Deputy Head of the Laboratory of Contemporary European Fertility and Family Dynamics.

(C) Copyright is held by the authors.

Working papers of the Max Planck Institute for Demographic Research receive only limited review. Views or opinions expressed in working papers are attributable to the authors and do not necessarily reflect those of the Institute. 


\begin{abstract}
A number of studies show that premarital cohabitation increases the risk of subsequent marital dissolution. Some argue that this is a consequence of selection effects and that once these are controlled for premarital cohabitation has no effect on dissolution. We extend this research by examining whether the effects of premarital cohabitation on marital dissolution vary across settlements within a country. Using retrospective event-history data from Austria, we model equations for union formation and dissolution jointly to control for unobserved selectivity of cohabiters or noncohabiters. Our results show that those who cohabit prior to marriage have a higher risk of marital dissolution. However, once selection effects are controlled for, the risks of marital dissolution for those who cohabit prior to marriage are significantly lower than for those who marry directly. We show that strong selection effects relate to both cohabitation and direct marriage and these effects are consistent across all settlements.
\end{abstract}

Keywords: union dissolution, urban, rural, event-history analysis, Austria 


\section{Introduction}

The number of marriages ending in divorce rose rapidly in most developed nations during the 1970s and 1980s. Although the rates have begun to stabilise in the 1990s in some countries, they continue to rise in others. Using data from 15 of the European countries (and the US) who participated in the Fertility and Family Surveys (FFS) conducted between 1989 and 1997, Andersson (2003) shows that in the US $42 \%$ of all marriages end in dissolution within 15 years. In Austria, the country which we examine here, the corresponding figure was $25 \%$, which was around average for the EU. Given the increasing scale of the problem, there is clearly a need to understand the complex causes of marriage dissolution.

Numerous factors have been shown to be related to marriage dissolution, including: women's increasing financial independence as their role in the labour market grows (Becker 1981, Hoem and Hoem 1992) and gender inequalities in wages gradually diminish (Davis and Joshi 1998); changes in gender roles (Kalmijn et al. 2004, Lye and Biblarz 1993); factors related to the parental home, including parental separation (Amato 1996, Kiernan 1986); personal characteristics, such as educational qualifications (Hoem 1997a, Morgan and Rindfuss 1985) and religious attitudes (Balakrishnan et al. 1987, Kalmijn et al. 2005); as well as demographic factors, such as the presence of one's own children (Erlangsen and Andersson 2001, Hoem 1997b, Morgan and Rindfuss 1985, Waite and Lillard 1991), the duration of the union (Chan and Halpin 2003), the age at union formation (Tzeng and Mare 1995), the age gap between the partners (Chan and Halpin 2003), the number of previous unions (O’Connor et al. 1999), and migration and mobility histories (Boyle et al. 2006, Muszynska and Kulu 2006).

An additional factor which has generated considerable debate in the literature is the role of premarital cohabitation which is becoming an increasingly common phenomenon (Bumpass et al. 1991). According to some theoretical arguments, we might expect premarital cohabitation to help stabilise subsequent married relationships because those who cohabit will gain more information about their spouse than those who do not live together. Cohabiting partners who found they were well suited might consider marriage, while those who found they were incompatible would end the cohabitation (Macklin 1978, Teachman et al. 1991). Such 'trial marriages' 
(Bennett et al. 1988) involve relatively low investment and are therefore easier to terminate; unsuccessful partnerships are effectively 'weeded out' (Cherlin 1981, Klijzing 1992, Macklin 1978). Indeed, most young adults appear to believe that cohabitation improves the chances of a subsequent marriage (Johnson et al. 2002, as quoted in Kline et al. 2004), suggesting that lay people's views about premarital cohabitation concur with this theoretical perspective.

However, the majority of empirical studies find that premarital cohabitation leads to higher risks of subsequent marital dissolution compared to couples who married without prior cohabitation (Wagner and Weiss 2004). Bennett et al. (1988), Hoem and Hoem (1992) and Trussell et al. (1992) find this effect in Sweden, as do Axinn and Thornton (1992), Bumpass et al. (1991), DeMaris and Rao (1992), Schoen (1992), Teachman and Polonko (1990), Teachman et al. (1991) and Thomson and Colella (1992) in the US, Balakrishnan et al. (1987), Hall and Zhao (1995) and Rao and Trussell (1989) in Canada, Bracher et al. (1993) in Australia, Manting (1992) and Klijzing (1992) in the Netherlands, Berrington and Diamond (1999) and Haskey (1992) in Britain, and Kiernan (2002a) in a number of Western European countries. Indeed, premarital cohabitation is also associated with lower marital satisfaction (Brown and Booth 1996), higher rates of wife infidelity (Forste and Tanfer 1996), and lower commitment to the partnership (Stanley et al. 2004). While there is some limited evidence that the effect of premarital cohabitation on the risk of marital dissolution may have reduced for more recent birth cohorts (Schoen 1992, Brown et al. 2006), other recent research suggests this is not the case (Dush et al. 2003). Overall, then, the consistency of these results in a number of countries makes this finding particularly persuasive and raises the question of why the 'trial marriage' theory may be invalid.

Some suggest that the duration of the union has an effect on this relationship. Bennett et al. (1988) and Thomson and Colella (1992) found that marriages were more susceptible to divorce for those who cohabited for longer periods of time. Teachman and Polonko (1990) found that while prior cohabitation had a negative effect on subsequent marriage duration once the duration of the entire union was accounted for the effect disappeared. Similarly, Hall (1996) found that those who cohabited for at least one year prior to marriage did not have a higher risk of marriage dissolution. However, duration of prior cohabitation was not found to influence 
subsequent marital instability by Lillard et al. (1995) - short cohabitations appeared to offer no advantage compared to longer cohabitations. More recently, Kline et al. (2004) show that those who are engaged at the point when the couple starts cohabiting are at much less risk of subsequent marital break-up. Hence, commitment to the relationship appears to be an important aspect influencing later partnership success (Stanley and Markman 1992).

The fact that premarital cohabitation appears to have a negative effect on marriage dissolution is often assumed to be a selection effect. Cohabiters may have unobserved characteristics which make them more prone to separation, such as less conventional attitudes about marriage and, perhaps, higher expectations about the quality of unions, or poorer relationship skills (Bennett et al. 1988, Hall 1999, Smock 2000, Thomson and Colella 1992). For example, we know that those who cohabit tend to be more liberal, less religious, and more supportive of eqalitarian gender roles (Clarkberg et al. 1995, Lye and Waldron 1997). For cohabiters, relationships in general, be they marital or non-marital, may be characterised by a lack of commitment and stability and they may be more willing to contemplate divorce if a marriage proves unsatisfactory (Bennett et al. 1988). Early studies seemed to support this selection hypothesis; Carlson (1986) reports that cohabiters were much more likely to view marriage as a response to social pressure than married couples, while Axinn and Thornton (1992) showed that cohabitation was selective of those who were less committed to marriage and more approving of divorce.

A second hypothesis is that the experience of cohabiting may also change people's views about marriage, making them less strongly committed to the institution (Axinn and Barber 1997, Axinn and Thornton 1992, DeMaris and Leslie 1984, Hall and Zhao 1995, Magdol et al. 1998, Thomson and Colella 1992). Through cohabitation, people may come to accept the temporary nature of relationships, and to recognise that there are alternative arrangements to more formal marriage. In addition, Stanley and Markman's (1997) 'inertia theory' suggests that:

"Some individuals want a test because they are aware of relationship problems or risks and that these individuals become more likely to marry by cohabiting, not because they solve problems or reduce risks, but because cohabiting makes it harder to break up." (Kline et al. 2004: 312.) 
Of course, it is also possible that both selection and causation effects are operating concomitantly, although it may be difficult to tease out the influence of one over the other empirically.

In an influential paper, Lillard et al. (1995) examined selection effects explicitly, recognising that some people choose to cohabit because they fear that marriage may not be successful. They applied a two-stage model which simultaneously considered the factors which influenced the choice to cohabit and the factors which influenced marital dissolution. The strategy explicitly recognised that the decision to cohabit prior to the marriage may be endogenous to subsequent divorce and this was accounted for by allowing the unobserved heterogeneity to be correlated across the two decisions. Their results demonstrated that observed differences in union dissolution between married couples who had and had not cohabited previously disappeared once these selection effects were accounted for.

Lillard et al's. (1995) approach has since been tested, with varying degrees of support. Woods and Emery (2002) find that controlling for selection effects eliminates the significant relationship between premarital cohabitation and marital instability, as do Steele et al. (2006). And, controlling for selection effects in a German study Bruderl et al. (1997) find that cohabitation actually decreases the risk of divorce, suggesting that gathering information about the spouse during this period does have a positive effect on subsequent marital stability. At the very least, these findings suggest that accounting for potential selection effects is critical when examining the influence of premarital cohabitation on subsequent marital dissolution.

Recently, there has also been some interest in geographical variations in the effect of premarital cohabitation on subsequent married partnerships. Kiernan (2002b) shows that while the increased risk of union dissolution among former cohabiters does exist in some European countries, in others it does not; indeed, the variation is quite considerable, perhaps suggesting that structural features of different societies may be influencing this pattern. Liefbroer and Dourleijn (2006) hypothesised that these variations would be influenced by how common cohabitation was in each country, pointing to the role of diffusion processes. Building on work by Schoen (1992), they hypothesised a U-shaped relationship, with premarital cohabitation leading to higher 
risks of subsequent marital dissolution in countries where cohabitation was a particularly rare or particularly common event. If few people in the population cohabit, those who do so will be a select group within the population, perhaps with less strongly held views about the sanctity of marriage. On the other hand, if most people in the population cohabit prior to marriage, then those who marry directly will be a select group, perhaps holding strong views about the institution of marriage (Hoem and Hoem 1992). In countries where premarital cohabitation is neither particularly common nor rare, selection effects may be expected to have a less significant role. The results of analyses of FFS data from 16 countries within Europe do indeed show that in countries where approximately $50 \%$ of couples practice cohabitation, former cohabiters have about the same risk of marriage dissolution as those who married without prior cohabitation (Austria was one of these countries). In countries where cohabitation is either very common or very rare, the risks associated with premarital cohabitation were shown to rise.

This paper contributes to this field of research in two important ways. First, following Lillard et al. (1995) we examine the relationship between premarital cohabitation and marital stability, controlling for potential selectivity by modelling the processes of union formation and dissolution simultaneously. Few contemporary studies have adopted this approach, and none have been conducted in Austria. Second, we extend the work of Liefbroer and Dourleijn (2006) to examine whether geographical variations in the practice of cohabitation influences the success or otherwise of subsequent marital arrangements within a nation. Significant urban-rural variations in divorce and separation exist, with those living in, or growing up in, urban areas being more likely to separate than those in rural areas (Balakrishnan et al. 1987, Lillard et al. 1995, South 2001, South et al. 2001). Regional differences have also been highlighted in the UK, with higher divorce and cohabitation rates in southern England, compared to Northern England and Scotland (Berrington and Diamond 1999). Assuming, therefore, that the influence of premarital cohabitation on subsequent marital stability varies in relation to the prevalence of cohabitation at a national level (Liefbroer and Dourleijn 2006), we might expect that similar processes will also operate within nations. Thus, we might expect the effect of premarital cohabitation to be most significant in Vienna, where cohabitation is most common, and in rural areas, where cohabitation is least common. In between these extremes 
(smaller urban areas and other cities), we expect the effect to be minimised. Do we find that selection effects vary geographically?

We use data from the Austrian Family and Fertility Survey (FFS) to examine union dissolution among three groups: cohabiters; those who married directly; and those who married following a spell of cohabitation. The Austrian rates of union dissolution (Andersson 2003) and cohabitation (Kiernan 2004) are about average for the EU and, according to Kiernan (2002b), Austria is a country, like Norway, Finland and Latvia, where premarital cohabitation does not appear to have an influence on subsequent marital dissolution. We might therefore expect that cohabiters will have higher rates of partnership breakdown than married couples, but that rates of dissolution will be similar for married couples who did and did not cohabit previously. Unlike Kiernan's (2002b) analysis, though, we also examine whether possible selection effects influence this apparent relationship. We test explicitly for the possibility that the decision to cohabit prior to marriage is a potentially endogenous variable in the dissolution process.

\section{Data}

The retrospective event-history data for this analysis were drawn from the Austrian Family and Fertility Survey (FFS) conducted in 1995-6. This was one of a sweep of surveys conducted in a number of European nations, Canada, New Zealand and the United States. The surveys included mainly consistent questions, but there were some variations and a particular advantage of the Austrian survey is that it included detailed retrospective partnership and residential histories, allowing us to identify where individuals were living at the time of a particular union. New spells were therefore defined as occurring when a woman changed partner or changed residential location, making this a valuable dataset for exploring geographical variations in marital dissolution (Boyle et al. 2006).

The response rate for the Austrian survey was an impressive 72\% (Hoem et al. 2001), resulting in 4,581 female and 1,539 male respondents born between 1941 and 1976. As in many other studies (e.g. Berrington and Diamond 1999), the nature of the data meant that unions were defined based on the co-residence of two intimate 
(heterosexual) partners. 'Living apart together' couples were impossible to identify and would therefore have been treated as separated, but this was likely to involve few cases (we observed only a small number of cases where a woman had more than one union with the same partner; the number of couples who lived apart and then cohabited again was small). Even if at least one of the partners was a weekly commuter the couple was regarded as living together. We excluded those born outside Austria, those living abroad at age 15 and those for whom significant parts of the data were incomplete, leaving 3,804 women of whom 3,118 had been in union (at least once) during their life and were therefore included in our analysis.

We constructed a multi-episode data-set for union dissolutions where individuals are at risk from union formation and followed until union dissolution, interview or death (if not separated). Of the 3,118 women who had at least one partnership, 397 had a second, 62 had a third and 10 had a fourth union. The number of union dissolutions was 669, 103, 22 and 1, respectively. Separations outside Austria and after return to Austria were excluded (a total of 22 events). We were particularly concerned with the dissolution rates for: cohabiters; those who married directly; and those who married following a spell of cohabitation. In addition, we disaggregated Austria into three broad geographical regions: the capital city of Vienna; the remaining cities and towns; and rural areas. According to the United Nations (2002) in 1995 about 26\% of the population lived in Vienna, about $41 \%$ in the smaller cities and towns, and about $33 \%$ in rural areas.

We included a range of time-varying and time-constant demographic and socioeconomic explanatory variables in the models presented below. These were identified from the literature reviewed above and include variables relating to family structure, women's independence, migration and mobility and qualifications (Table 3 provides a list of the variables and their sub-categories).

\section{Methods}

We modelled the time from union formation to dissolution using a series of hazard regression models (Allison 1984, Blossfeld and Rohwer 1995, Hoem 1987, 1993). We were particularly interested in whether marital dissolution was influenced by 
premarital cohabitation, controlling for a range of other factors, as represented by equation 1:

$$
\ln \mu_{i j}(t)=y(t)+\sum_{k} z_{k}\left(u_{i j k}+t\right)+\sum_{l} \alpha_{l} x_{i j l}+\sum_{m} \beta_{m} w_{i j m}(t)
$$

where $\mu_{i j}(t)$ denotes the hazard of the $j$ th union dissolution for individual $i$ and $y(t)$ denotes a piecewise linear spline that captures the impact of baseline (i.e. union) duration on the hazard ${ }^{1}$. The parameter $z_{k}\left(u_{i j k}+t\right)$ denotes the spline representation of the effect of a time-varying variable that is a continuous function of $t$ with origin $u_{i j k}$ (e.g. a woman's age). The parameter $x_{i j l}$ represents the values of a time-constant variable (e.g. parental divorce) and $w_{i j m}(t)$ represents a time-varying variable whose values can change only at discrete times (e.g. place of residence or partnership status).

A crucial part of the modelling was to investigate the possible role of unobserved selectivity bias (see Figure 1). In particular, we were interested in whether the apparent relationship between marital dissolution and premarital cohabitation would be consistent once the unmeasured characteristics of those who enter cohabitation were accounted for - the aim was to identify possible endogeneity of cohabiting in the union dissolution process. Thus, we built a simultaneous-equations model to estimate jointly an equation for union dissolution, and two equations for partnership formation (distinguishing between marriage and cohabitation). Person-specific heterogeneity terms were included in all three equations, allowing us to test for a correlation between these residual terms (cf. Lillard et al. 1995). The simultaneous equations model can be formalised as:

$$
\begin{aligned}
& \ln \mu_{i j}^{D}(t)=y^{D}(t)+\sum_{k} z_{k}^{D}\left(u_{i j k}+t\right)+\sum_{l} \alpha_{l}^{D} x_{i j l}+\sum_{m} \beta_{m}^{D} w_{i j m}(t)+\varepsilon_{i}^{D} \\
& \ln \mu_{i j}^{C}(t)=y^{C}(t)+\sum_{k} z_{k}^{C}\left(u_{i j k}+t\right)+\sum_{l} \alpha_{l}^{C} x_{i j l}+\sum_{m} \beta_{m}^{C} w_{i j m}(t)+\varepsilon_{i}^{C} \\
& \ln \mu_{i j}^{M}(t)=y^{M}(t)+\sum_{k} z_{k}^{M}\left(u_{i j k}+t\right)+\sum_{l} \alpha_{l}^{M} x_{i j l}+\sum_{m} \beta_{m}^{M} w_{i j m}(t)+\varepsilon_{i}^{M}
\end{aligned}
$$

\footnotetext{
${ }^{1}$ We used a piecewise linear spline specification (instead of the widely used piecewise constant approach) to pick up the baseline log-hazard and the effect of (other) time-varying variables that change continuously. Parameter estimates are thus slopes for linear splines over user-defined time periods. With sufficient nodes (bend points) piecewise linear-specification can efficiently capture any log-hazard pattern in the data.
} 
where $\mu_{i j}{ }^{D}(t)$ denotes the hazard of the $j$ th union dissolution, $\mu_{i j}{ }^{C}(t)$ and $\mu_{i j}{ }^{M}(t)$ represent the risk of transition to jth cohabitation or direct marriage in the competing risk framework. The parameters $\varepsilon_{i}{ }^{D}, \varepsilon_{i}{ }^{C}$ and $\varepsilon_{i}{ }^{M}$ are person-specific heterogeneity terms for the dissolution, cohabitation and marriage equations, respectively. We assumed that the residuals would follow a joint tri-variate normal distribution:

$$
\left(\begin{array}{l}
\varepsilon_{i}^{D} \\
\varepsilon_{i}^{C} \\
\varepsilon_{i}^{M}
\end{array}\right) \sim N\left(\left(\begin{array}{l}
0 \\
0 \\
0
\end{array}\right),\left(\begin{array}{ccc}
\sigma_{\varepsilon^{D}}^{2} & \rho_{\varepsilon^{c} \varepsilon^{D}} & \rho_{\varepsilon^{M} \varepsilon^{D}} \\
\rho_{\varepsilon^{D} \varepsilon^{C}} & \sigma_{\varepsilon^{c}}^{2} & \rho_{\varepsilon^{M} \varepsilon^{c}} \\
\rho_{\varepsilon^{D} \varepsilon^{M}} & \rho_{\varepsilon^{c} \varepsilon^{M}} & \sigma_{\varepsilon^{M}}^{2}
\end{array}\right)\right),
$$

where $\sigma_{\varepsilon^{D}}^{2}, \sigma_{\varepsilon^{c}}^{2}$ and $\sigma_{\varepsilon^{M}}^{2}$ denote the variances of the person-specific residuals and $\rho_{\varepsilon^{D} \varepsilon^{c}}, \rho_{\varepsilon^{D} \varepsilon^{M}}, \rho_{\varepsilon^{c} \varepsilon^{M}}$ are the correlations between the residuals ${ }^{2}$.

The identification of our model was attained through within-person replication: some women had experienced several partnerships and separations during the observation period (see Lillard et al.1995; Kulu 2005; 2006). The parameters were obtained using maximum likelihood estimation and the standard errors of the estimates were corrected using a Huber-type procedure (Huber 1967).

\section{Results}

The descriptive results in Table 1 show that, as expected, single and separated people were most likely to enter marriage directly in rural areas, while entering cohabitation was much more common in urban areas, especially in Vienna. Table 2 presents the number of person years in different partnership categories by geographical location, thus providing further information on the dominance of different relationships across settlements. As expected, years spent in direct marriages were most common in all settlements, but their share was largest in rural areas and smallest in Vienna. Thus, we find that different types of partnership do indeed vary considerably across different urban/rural settings within Austria.

\footnotetext{
${ }^{2}$ The correlation between the residuals from the cohabitation and direct marriage equations was not estimated, as this is not focused upon in our analysis.
} 
Table 3 provides the results for five models, which become increasingly complex. In model 1 we consider the effect of partnership status on union dissolution, controlling only for the duration of the relationship and the age of the woman. Cohabiters were most likely to separate and those that cohabited prior to marriage were significantly more likely to separate than those who married directly. As described above, this is in line with the majority of previous studies that examine this relationship, although it is different to the result provided by Kiernan (2002b) where no significant difference was found between those who married directly and those who married following cohabitation in Austria. However, Kiernan (2002b) controlled for parental divorce in her model and when we extend our model to control for a range of demographic and socio-economic variables, we find that the effect indeed becomes insignificant (model 2, Table 3).

In model 3 (Table 3) we include separate partnership status parameters for each of our three geographical regions, controlling only for the duration of the relationship and the age of the woman. Figure 2 displays the relative risks calculated for the nine resulting partnership/geographical status groups. Overall, risks of dissolution were highest in Vienna and lowest in rural areas for all three partnership categories. In all three geographical regions, the risk of union dissolution was considerably higher for cohabiters than for the married, with the highest risk of all for those living in Vienna. For the married, those who cohabited prior to marriage had a higher risk of separation than those who married directly in both Vienna and rural areas, but not in the towns and cities, offering some marginal support for Liefbroer and Dourleijn's (2006) hypothesised U-shaped relationship. Note, however, that the risk for those in rural areas was not higher than the risk for those in towns and cities.

The relative risks of union dissolution reduced considerably for cohabiters once the additional demographic and socio-economic explanatory variables were included in the model, although they still remained higher than for the married (model 4, Table 3 and Figure 3; note the scale of the y axis is different in Figures 2 and 3). Once these additional variables were controlled for, the risks of dissolution were broadly similar for married couples who did and did not cohabit prior to marriage in all three geographical areas. 
We extended the analysis in model 5 (Table 3) by fitting a simultaneous equations model which included the equation for union dissolution, as fitted in model 4 , and separate equations of the risk of marriage and cohabitation for single and separated people. This allowed us to test whether partnered women who cohabit/marry directly have unobserved characteristics which make them more or less prone to subsequent marital union dissolution. Each equation also included person-specific residuals and the correlations are reported at the end of model 5 (Table 3). The significant positive correlation between the cohabitation and dissolution models (0.413) demonstrates that women who cohabit have unobserved characteristics that increase the risk of union dissolution, while the significant negative correlation between marriage and dissolution (-0.414) demonstrates that women who marry directly have unobserved characteristics that decrease the risk of union dissolution.

These results support the findings of Lillard et al. (1995) and demonstrate the importance of controlling for selection effects when examining the role of premarital cohabitation on marriage dissolution. However, our results are even more dramatic than those presented by Lillard et al. (1995). In their study an apparent negative effect of premarital cohabitation became insignificant, once selection effects were accounted for. In this study the negative effect of premarital cohabitation switched to a positive effect, once observed and unobserved selection effects were accounted for premarital cohabitation actually decreased the risk of marital separation, at least in Vienna and the other cities and towns (Figure 4). Similar to the results in model 4, we also found that the risks of dissolution were highest for all three partnership groups in Vienna and lowest in the rural areas, and we found no evidence of a U-shaped relationship as the risk for married people who had cohabited in rural areas was no higher than the risk in the towns and cities ${ }^{3}$.

Comparing the relative risks in Figures 3 and 4, we see rather proportionate changes across settlements: the relative risks of dissolution of marriages preceded by cohabitation decreases to a similar degree in all three areas. Thus, strong selection effects are present in all three settlement types, and not only in those where

\footnotetext{
${ }^{3}$ Note, though, that while the risk of marital dissolution for those who cohabited prior to marriage was similar in rural areas and the towns and cities, the risk of dissolution for cohabiters and those who married directly were considerably smaller in rural areas compared to towns and cities. Relative to these outcomes, therefore, the risk of marital dissolution among those who cohabited prior to marriage was slightly greater in rural areas.
} 
cohabitation was most common (Vienna) or most rare (rural areas), as we might expect according to the hypothesis presented by Liefbroer and Dourleijn (2006):

"If the proportion of cohabiters and non-cohabiters is more or less in equilibrium, selection processes might still be operative, but certainly to a lesser extent than when the proportion of cohabiters is either very low or very high. As a result, the difference in union dissolution rates of people who married after cohabitation and of people who married straightaway will be much smaller." (Liefbroer and Dourleijn 2006: 206.)

\section{Discussion}

Given that an increasingly high proportion of marriages end in separation, it is important to understand more about the factors which cause dissolution. Here, we focused on the role of premarital cohabitation, the influence of which has been debated for some time. Cohabitation has become increasingly common for young adults, with over one half of persons in their twenties and thirties in the US having experienced cohabitation (Bumpass and Lu 2000; see also Brown 2005, Casper and Cohen 2000, Smock 2000) and over 70\% of first partnerships being cohabitations in the UK (Ermisch and Francesconi 2000). There has also been a sharp increase in premarital cohabitation in many developed societies (Bumpass et al. 1991, Ermisch 2005, Murphy 2000, Stanley et al. 2004). As a consequence, the influence of cohabitation on marital stability will become increasingly important in the future.

Despite theoretical reasoning to the contrary, numerous studies appear to show that premarital cohabitation increases the risk of subsequent marital dissolution. The most persuasive explanation for this counter-intuitive result is self-selection. Couples who cohabit prior to marriage may have a higher latent probability of divorce or separation than couples who marry directly. According to Svarer (2004), only Lillard et al. (1995) had corrected for the existence of such an effect, but their results showed that there was no significant difference in dissolution rates for married couples who had and had not cohabited prior to marriage (see also Woods and Emery 2002). More recently, Steele et al. (2006) used data from the 1970 British Cohort Study to explore the formation and dissolution of cohabiting and married unions for women born in 
Britain in 1970. Their results also showed that an apparently positive relationship between premarital cohabitation and marital dissolution disappeared once selection effects were accounted for. Hence, even after accounting for self-selection, both of these studies found no supporting evidence for a 'learning effect' where partners gather information about each other during cohabitation and only successful matches survive these 'trial marriages'.

We can find only two previous studies which show that prior cohabitation may indeed make marriages more stable, once selection effects are controlled. Using data from the West German Family Survey for 1988, Bruderl et al. (1997) show that net of selfselection effects, cohabitation prior to marriage decreased the risk of later divorce. Svarer (2004) also found this effect using recent register data for Denmark arguing that as premarital cohabitation becomes more common, the composition of the pool of cohabitants changes. Thus, it was speculated that as cohabitation is becoming the norm in much of Europe, this pattern may start to dominate.

The first aim of our research was therefore to examine whether premarital cohabitation influences subsequent marital dissolution in Austria, controlling for selection effects using a simultaneous modelling approach, testing the assumption that those who decide to cohabit prior to marriage may be more prone to relationship breakdown than other equivalent people. Indeed, some couples may choose to cohabit initially because a marriage would have a high risk of failure, but for various reasons choose to marry after living together for some time. In this case, premarital cohabitation would certainly be endogenous to the subsequent dissolution process (Lillard et al.1995).

The second goal of this research was to examine whether geographical context, within a single nation, influences this result. The processes which shape demographic life events are influenced by individual characteristics, but they are also likely to be influenced by national and regional institutional structures and attitudes to different marital arrangements (e.g. Blossfeld 1995, Holdsworth and Elliott 2001, Lesthaeghe 1998, Neyer and Andersson 2004). Kiernan (2002b) shows that in some European countries, such as France, Germany and Sweden, those who cohabit prior to marriage have a higher risk of marital dissolution, while in other countries, such as Austria, Finland, Latvia and Norway, this is not the case. Here we extend this argument to 
investigate the role of contextual effects within a single nation (see also Pollard and $\mathrm{Wu}$ 1998). Building on research by Liefbroer and Dourleijn (2006), our analysis examined intra-nation variations in the impact of premarital cohabitation on subsequent separation among women in Austria by comparing the effects across settlements with different rates of premarital cohabitation.

Controlling for selectivity effects had a substantial impact on our results. Lillard et al. (1995) found that a sizeable effect of premarital cohabitation on subsequent marital dissolution disappeared once unobserved selectivity was accounted for; the original effect was due entirely to the selection of the most divorce-prone into cohabitation. In the Austrian case, once we correct for the selection of those most prone to separation into premarital cohabitation and those least prone to separation into direct marriage, we find that cohabitation - net of self-selection - actually decreases the risk of separation. These results are similar to those of Bruderl et al. (1997) in West Germany and Svarer (2004) in Denmark. Thus, it would appear that the trial marriage' theory may indeed be relevant, with premarital cohabitation providing information which allows for a more precise estimate of the match quality with the prospective spouse. As a consequence, marriages that involve prior cohabitation are more stable than direct marriages.

We found little evidence to support Liefbroer and Dourleijn's (2006) U-shaped curve argument within Austria. While rates of marital dissolution for those who cohabited prior to marriage were highest in Vienna, which had the highest cohabitation rates, there was no corresponding rise in rates in rural areas, where the share of cohabiters was lowest. For both cohabiters and those who married directly, the risk of dissolution rose reasonably linearly: the risks in rural areas were lowest, followed by the risks in the towns and cities, and the risks in Vienna were highest. For those who cohabited prior to marriage the risks of marital dissolution were similar for those in rural areas and the towns and cities.

Finally, our results do suggest that there are significant geographical variations in union dissolution within Austria. Separation rates were highest in Vienna for cohabiters, as well as for those who married directly and those who married following cohabitation. Indeed, separation rates among those who married directly in Vienna were even higher than the separation rates for cohabiters in rural areas and the towns 
and other cities. The separation rates were lowest for all three partnership groups in the rural areas. Given that we control for a range of individual characteristics in our models, these results provide convincing support for the notion that 'context' influences social and demographic processes (Harding 2003, Lee et al. 1994). We also explored whether controlling for selection effects had different impacts in the three types of geographical area and demonstrated that the effects were reasonably consistent across settlements.

Our results provide the first examination of the "cohabitation and direct marriage effects' by geographical context within a nation. Within the field of demography there has been a growing interest in 'contextualising' demographic processes. However, most of this research focuses on cross-national variation, ignoring more detailed local variations that might occur within nations. Here we argued that the diffusion processes which Liefbroer and Dourleijn (2006) claim should influence the effect of premarital cohabitation on subsequent marital stability at a national level should also be expected to influence patterns within nations. Our results, which control for selection effects do not, however, provide strong support for this effect. Instead, strong selection processes in relation to both cohabitation and direct marriage operate where cohabitation is relatively rare (rural areas), relatively common (Vienna), but also in those places in between. Our research thus suggests that studies examining the effect of premarital cohabitation on marital dissolution should explicitly address observed and unobserved selectivity into cohabitation and direct marriage as part of the analysis.

\section{Acknowledgements}

We thank the Max Planck Institute for Demographic Research (MPIDR) for funding, which supported Paul Boyle's research stay at the Laboratory of Contemporary European Fertility and Family Dynamics of the MPIDR. 


\section{References}

Allison, P. 1984. Event History Analysis: Regression for Longitudinal Event Data. Quantitative Applications in the Social Sciences 46. Newbury Park: Sage.

Amato, P.R. 1996. "Explaining the Intergenerational Transmission of Divorce." Journal of Marriage and the Family 58:628-40.

Andersson, G. 2003. "Dissolution of Unions in Europe: A Comparative Overview." MPIDR, Working Paper WP-2003-004. Rostock: Max Planck Institute for Demographic Research.

Axinn, W.G. and J.S. Barber. 1997. "Living Arrangement and Family Formation Attitudes in Early Adulthood." Journal of Marriage and the Family 59:595611.

Axinn, W.G. and A. Thornton. 1992. "The Relationship between Cohabitation and Divorce: Selectivity or Causality?" Demography 29:357-74.

Balakrishnan, T.R., K.V. Rao, E. LaPierre-Adamcyk and K.J. Krotki. 1987. "A Hazard Model Analysis of the Covariates of Marriage Dissolution in Canada." Demography 24:395-406.

Becker, G.S. 1981. A Treatise on the Family. Cambridge: Harvard University Press. Bennett, N., A. Blanc and D. Bloom. 1988. "Commitment and the Modern Union: Assessing the Link between Premarital Cohabitation and Subsequent Marital Stability." American Sociological Review 53:127-38.

Berrington, A. and I. Diamond. 1999. "Marital Dissolution among the 1958 British Birth Cohort: The Role of Cohabitation." Population Studies 53:19-38.

Blossfeld, H.-P. 1995. "Changes in the Process of Family Formation and Women's Growing Economic Independence: A Comparison of Nine Countries." Pp. 334 in The New Role of Women: Family Formation in Modern Societies, edited by H.-P. Blossfeld. Boulder: Westview.

Blossfeld, H.-P. and G. Rohwer. 1995. Techniques of Event History Modeling: New Approaches to Causal Analysis. Mahwah: Lawrence Erlbaum Associates.

Boyle, P.J., H. Kulu, T. Cooke, V. Gayle and C.H. Mulder. 2006. "The Effect of Moving on Union Dissolution.” MPIDR, Working Paper WP-2006-002. Rostock: Max Planck Institute for Demographic Research.

Bracher, M., G. Santow, S.P. Morgan and J. Trussel. 1993. "Marriage Dissolution in Australia: Models and Explanations." Population Studies 47:403-25.

Brown, S.L. 2005. "How Cohabitation is Reshaping American Families." Contexts 4:33-37.

Brown S.L. and Booth A. 1996. "Cohabitation versus Marriage: A Comparison of Relationship Quality." Journal of Marriage and the Family 58: 668-678.

Brown, S.L., L.A. Sanchez, S.L. Nock and J.D. Wright. 2006. "Links between Premarital Cohabitation and Subsequent Marital Quality, Stability, and Divorce: A Comparison of Covenant versus Standard Marriage." Social Science Research 35:454-70.

Bruderl, J., A. Diekmann and H. Engelhardt. 1997. "Premarital Cohabitation and Marital Stability in West Germany.“ Kölner Zeitschrift für Soziologie und Sozialpsychologie 49:205-22.

Bumpass, L.L. and H.H. Lu. 2000. "Trends in Cohabitation and Implications for Children's Family Contexts in the United States." Population Studies 54:2941.

Bumpass, L.L., J.A. Sweet and A. Cherlin. 1991. "The Role of Cohabitation in Declining Rates of Marriage." Journal of Marriage and the Family 53:91327. 
Carlson, E. 1986. "Couples without Children: Premarital Cohabitation in France.” Pp. 113-29 in Contemporary Marriage: Comparative Perspectives of a Changing Institution, edited by K. Davis and A. Grossbard-Schechtman. New York: Russell Sage Foundation.

Casper, L.M. and P.N. Cohen. 2000. "How does POSSLQ Measure up? Historical Estimates of Cohabitation." Demography 37:237-45.

Chan, T.W. and B. Halpin. 2003. "Union Dissolution in the United Kingdom." International Journal of Sociology 32:76-93.

Cherlin, A. 1981. Marriage, Divorce, Remarriage. Cambridge: Harvard University Press.

Clarkberg, M.E., R.M. Stolzenberg and L.J. Waite. 1995. "Attitudes, Values, and Entrance into Cohabitational versus Marital Unions." Social Forces 74: 609-34.

Davies, H. and Joshi, H. 1998. "Gender and Income Inequality in the UK 1968-1990: The Feminization of Earnings or of Poverty? Journal of the Royal Statistical Society A 161:33-61.

DeMaris, A. and G.R. Leslie. 1984. "Cohabitation with Future Spouse: Its Influence upon Marital Satisfaction and Communication." Journal of Marriage and the Family 46:77-84.

DeMaris, A. and V. Rao. 1992. "Premarital Cohabitation and Subsequent Marital Stability in the United States: A Reassessment." Journal of Marriage and the Family 54:178-90.

Dush, C.M.K., C.L. Cohan and P.R. Amato. 2003. "The Relationship between Cohabitation and Marital Quality and Stability: Change across Cohorts?" Journal of Marriage and the Family 65:539-49.

Erlangsen, A. and G. Andersson. 2001. "The Impact of Children on Divorce Risks in First and Later Marriages." MPIDR, Working Paper WP-2001-033. Rostock: Max Planck Institute for Demographic Research.

Ermisch, J. 2005. "The Puzzling Rise of Childbearing Outside Marriage.” Pp. 22-53 in Understanding Social Change, edited by A. Heath, J. Ermisch and D. Gallie. Oxford: Oxford University Press.

Ermisch, J. and M. Francesconi. 2000. "Cohabitation in Great Britain: Not for Long, but Here to Stay." Journal of the Royal Statistical Society A 163:153-71.

Forste, R. and Tanfer, K. 1996. "Sexual Exclusivity among Dating, Cohabiting, and Married Women." Journal of Marriage and the Family 58:33-47.

Hall, DR. 1996. "Marriage as a Pure Relationship: Exploring the Link between Premarital Cohabitation and Divorce in Canada." Journal of Comparative Family Studies 27: 1-12.

Hall, D.R. and J.Z. Zhao. 1995. "Cohabitation and Divorce in Canada: Testing the Selectivity Hypothesis." Journal of Marriage and the Family 57:421-27.

Harding, D.J. 2003. "Counterfactual Models of Neighborhood Effects: The Effect of Neighborhood Poverty on Dropping Out and Teenage Pregnancy." American Journal of Sociology 109:676-719.

Haskey, J. 1992. "Premarital Cohabitation and the Probability of Subsequent Divorce: Analyses Using New Data from the General Household Survey." Population Trends 68:10-19.

Holdsworth, C. and J. Elliott. 2001. "The Timing of Family Formation in Britain and Spain." Sociological Research Online 6:U49-U72.

Hoem, B. and J.M. Hoem. 1992. "The Disruption of Marital and Non-marital Unions in Contemporary Sweden.” Pp. 61-93 in Demographic Applications of Event History Analysis, edited by J. Trussel, R. Hankinson and J. Tilton. Oxford: Clarendon Press. 
Hoem, J.M. 1987. "Statistical Analysis of a Multiplicative Model and its Application to the Standardization of Vital Rates: A Review." International Statistical Review 55:119-152.

Hoem, J.M. 1993. "Classical Demographic Models of Analysis and Modern Eventhistory Techniques." Stockholm Research Reports in Demography 75. Stockholm: Stockholm University, Demography Unit.

Hoem, J.M. 1997a. "Educational Gradients in Divorce Risks in Sweden in Recent Decades." Population Studies 51:19-27.

Hoem, J.M. 1997b. "The Impact of the First Child on Family Stability." Stockholm Research Reports in Demography 119. Stockholm: Stockholm University, Demography Unit.

Hoem, J.M., A. Prskawetz and G. Neyer. 2001. "Autonomy or Conservative Adjustment? The Effect of Public Policies and Educational Attainment on Third Births in Austria." Population Studies 55:249-261.

Huber, P. J. 1967. "The Behavior of Maximum Likelihood Estimates Under Nonstandard Conditions". Pp. 221-33 in Proceedings of the Fifth Berkeley Symposium on Mathematical Statistics and Probability. Berkeley: University of California Press.

Johnson, C.A., S.M. Stanley, N.D. Glenn, P.R. Amato, S.L. Nock, H.J. Markman. 2002. Marriage in Oklahoma: 2001 Baseline State-wide Survey on Marriage and Divorce. Oklahoma City: Oklahoma Department of Human Services.

Kalmijn, M., P.M. de Graaf and A.R. Poortman. 2004. "Interactions between Cultural and Economic Determinants of Divorce in the Netherlands." Journal of Marriage and the Family 66:75-89.

Kalmijn, M., P.M. de Graaf and J.P.G. Janssen. 2005. "Intermarriage and the Risk of Divorce in the Netherlands: The Effects of Differences in Religion and in Nationality, 1974-94." Population Studies 59:71-85.

Kiernan, K. 1986. "Teenage Marriage and Marital Breakdown: A Longitudinal Study." Population Studies 40:35-54.

Kiernan, K. 2002a. "Cohabitation in Western Europe: Trends, Issues, and Implications." Pp. 3-32 in Just Living Together: Implications of Cohabitation on Families, Children, and Social Policy, edited by A. Booth and A. Crouter. Mahwah: Erlbaum.

Kiernan, K. 2002b. "The State of European Unions: An Analysis of FFS Data on Partnership Formation and Dissolution." Pp. 57-76 in Dynamics of Fertility and Partnership in Europe: Insights and Lessons from Comparative Research. Volume 1, edited by M. Macura and G. Beets. New York: United Nations.

Kiernan, K. 2004. "Redrawing the Boundaries of Marriage." Journal of Marriage and Family 66:980-87.

Klijzing, E. 1992. "Weeding in the Netherlands: First-union Disruption among Men and Women Born between 1928 and 1965." European Sociological Review 8:53-70.

Kline, G.H., S.M. Stanley, H.J. Markman, P.A. Olmos-Gallo, M. St Peters, S.W. Whitton and L.M. Prado. 2004. "Timing is Everything: Pre-engagement Cohabitation and Increased Risk for Poor Marital Outcomes.” Journal of Family Psychology 18:311-18.

Kulu, H. 2005. "Migration and Fertility: Competing Hypotheses Re-examined." European Journal of Population 21:51-87.

Kulu, H. 2006. "Fertility of Internal Migrants: Comparison between Austria and Poland." Population, Space and Place 12:147-170.

Lee, B.A., R.S. Oropesa and J.W. Kanan. 1994. "Neighbourhood Context and Residential Mobility." Demography 31:249-70. 
Lesthaeghe, R. 1998. "On Theory Development: Applications to the Study of Family Formation." Population and Development Review 24:1-14.

Liefbroer, A.C. and E. Dourleijn. 2006. "Unmarried Cohabitation and Union Stability: Testing the Role of Diffusion using Data from 16 European Countries." Demography 43:203-21.

Lillard, L.A., M.J. Brien and L.J. Waite. 1995. "Premarital Cohabitation and Subsequent Marital Dissolution: A Matter of Self-selection?" Demography 32:437-57.

Lye, D.N. and T.J. Biblarz. 1993. "The Effects of Attitudes toward Family Life and Gender Roles on Marital Satisfaction.” Journal of Family Issues 14:157-188.

Lye, D.N. and I. Waldron. 1997. "Attitudes toward Cohabitation, Family, and Gender Roles: Relationships to Values and Political Ideology." Sociological Perspectives 40:199-25.

Macklin, E. 1978. "Nonmarital Heterosexual Cohabitation: A Review of the Recent Literature." Marriage and Family Review 1:1-12.

Magdol, L., T.E. Moffitt, A. Caspi and P.A. Silva. 1998. "Hitting Without a License: Testing Explanations for Differences in Partner Abuse between Young Adult Daters and Cohabitors." Journal of Marriage and the Family 60:41-55.

Manting, D. 1992. "The Break-Up of Unions: The Role of Cohabitation." PDOD, Working Paper no. 11. Amsterdam: University of Amsterdam

Morgan, S.P. and R.R. Rindfuss. 1985. "Marital Disruption: Structural and Temporal Dimensions." American Journal of Sociology 33:1055-77.

Murphy, M. 2000. "Editorial: Cohabitation in Britain." Journal of the Royal Statisical Society A 163:123-26.

Muszynska, M. and H. Kulu. 2006. "Migration and Union Dissolution in a Changing Socio-economic Context: The Case of Russia." MPIDR Working Paper, WP-2006-036. Rostock: Max Planck Institute for Demographic Research.

Neyer, G.R. and G. Andersson. 2004 (Eds.) Contemporary Research on European Fertility: Perspectives and Developments. Demographic Research, Special Collection 3. Rostock: Max Planck Institute for Demographic Research.

O'Connor, T.G., K. Pickering, J. Dunn and J. Golding. 1999. 'Frequency and Predictors of Relationship Dissolution in a Community Sample in England." Journal of Family Psychology 13:436-49.

Pollard, M.S. and Z. Wu. 1998. "Divergence of Marriage Patterns in Quebec and Elsewhere in Canada." Population and Development Review 24:329-56.

Rao, R.K. and J. Trussell. 1989. "Premarital Cohabitation and Marital Stability: A Reassessment of the Canadian Evidence: Feedback." Journal of Marriage and the Family 51:535-40.

Schoen, R. 1992. "First Unions and the Stability of First Marriages." Journal of Marriage and the Family 54:281-84.

Smock, P.J. 2000. "Cohabitation in the United States: An Appraisal of Research Themes, Findings, and Implications." Annual Review of Sociology 26:1-20.

South, S.J. 2001. "The Geographic Context of Divorce: Do Neighborhoods Matter?" Journal of Marriage and the Family 63:755-66.

South, S.J., K. Trent and Y. Shen. 2001. "Changing Partners: Toward a Macrostructural-opportunity Theory of Marital Dissolution." Journal of Marriage and the Family 63:743-54.

Stanley, S.M. and H.J. Markman. 1997. Marriage in the 90s: A Nationwide Random Phone Survey. Denver: PREP Inc.

Stanley, S.M. and H.J. Markman. 1992. "Assessing Commitment in Personal Relationships." Journal of Marriage and the Family 54:595-608. 
Stanley, S.M., S.W. Whitton and H.J. Markman. 2004. "Maybe I do: Interpersonal Commitment and Premarital or Nonmarital Cohabitation." Journal of Family Issues 25:496-519.

Steele, F., C. Kallis and H. Joshi. 2006. "The Formation and Outcomes of Cohabiting and Marital Partnerships in Early Adulthood: The Role of Previous Partnership Experience." Journal of the Royal Statisical Society A 169 (forthcoming).

Svarer, M. 2004. "Is Your Love in Vain? Another Look at Premarital Cohabitation and Divorce." Journal of Human Resources 39:523-35.

Teachman, J.D., J. Thomas and K. Paasch. 1991. "Legal Status and the Stability of Coresidential Unions." Demography 28:571-86.

Teachman, J.D. and K.A. Polonko. 1990. "Cohabitation and Marital Stability in the United States.” Social Forces 69:207-20.

Thomson, E. and U. Colella. 1992. "Cohabitation and Marital Stability: Quality or Commitment?" Journal of Marriage and the Family 54:259-67.

Trussell, J., G. Rodríguez and B. Vaughan. 1992. 'Union Dissolution in Sweden.” Pp. 38-60 in Demographic Applications of Event History Analysis, edited by J. Trussell, R. Hankinson and J. Tilton. Oxford: Clarendon Press.

Tzeng, J.M. and R.D. Mare. 1995. "Labor Market and Socioeconomic Effects on Marital Stability." Social Science Research 24:329-51.

United Nations. 2002. World Urbanization Prospects: The 2001 Revision. New York: United Nations.

Wagner, M. and B. Weiss. 2004. "On the Variation of Divorce Risks in Europe: A Meta-analysis." Paper prepared for "The Third Conference of the European Research Network on Divorce", University of Cologne, Germany, December 2-4.

Waite, L.J. and L.A. Lillard. 1991. "Children and Marital Disruption." American Journal of Sociology 96:930-53.

Woods, L. N. and R.E. Emery. 2002. The Cohabitation Effect on Divorce: Causation or Selection?" Journal of Divorce and Remarriage 37(3/4). 
Table 1 Geographical variation in union formation

\begin{tabular}{lcc}
\hline & Direct marriages (\%) & Cohabitations (\%) \\
\hline Singles in Vienna & 36 & 64 \\
Singles in towns and cities & 40 & 60 \\
Singles in rural areas & 51 & 49 \\
Total & 45 & 55 \\
\hline
\end{tabular}

Table 2 Geographical variation in union status

\begin{tabular}{lcc}
\hline & Person years & $\begin{array}{c}\text { Person years (within } \\
\text { region) } \\
\text { \% }\end{array}$ \\
\hline Cohabiting in Vienna & N & 18 \\
Married, after cohabitation in Vienna & 1346.00 & 30 \\
Married, directly in Vienna & 2195.51 & 52 \\
Total in Vienna & 3855.51 & 100 \\
& 7397.03 & 17 \\
Cohabiting in towns and cities & & 28 \\
Married, after cohabitation in towns and cities & 1908.67 & 55 \\
Married, directly in towns and cities & 3105.76 & 100 \\
Total in towns & 6227.11 & 12 \\
& 11241.54 & 22 \\
Cohabiting in rural areas & & 67 \\
Married, after cohabitation in rural areas & 2767.57 & 100 \\
Married, directly in rural areas & 5282.04 & \\
Total in rural areas & 15981.18 & \\
Total & 24030.79 & \\
\hline
\end{tabular}


Table 3 The factors influencing union dissolution (parameter estimates)

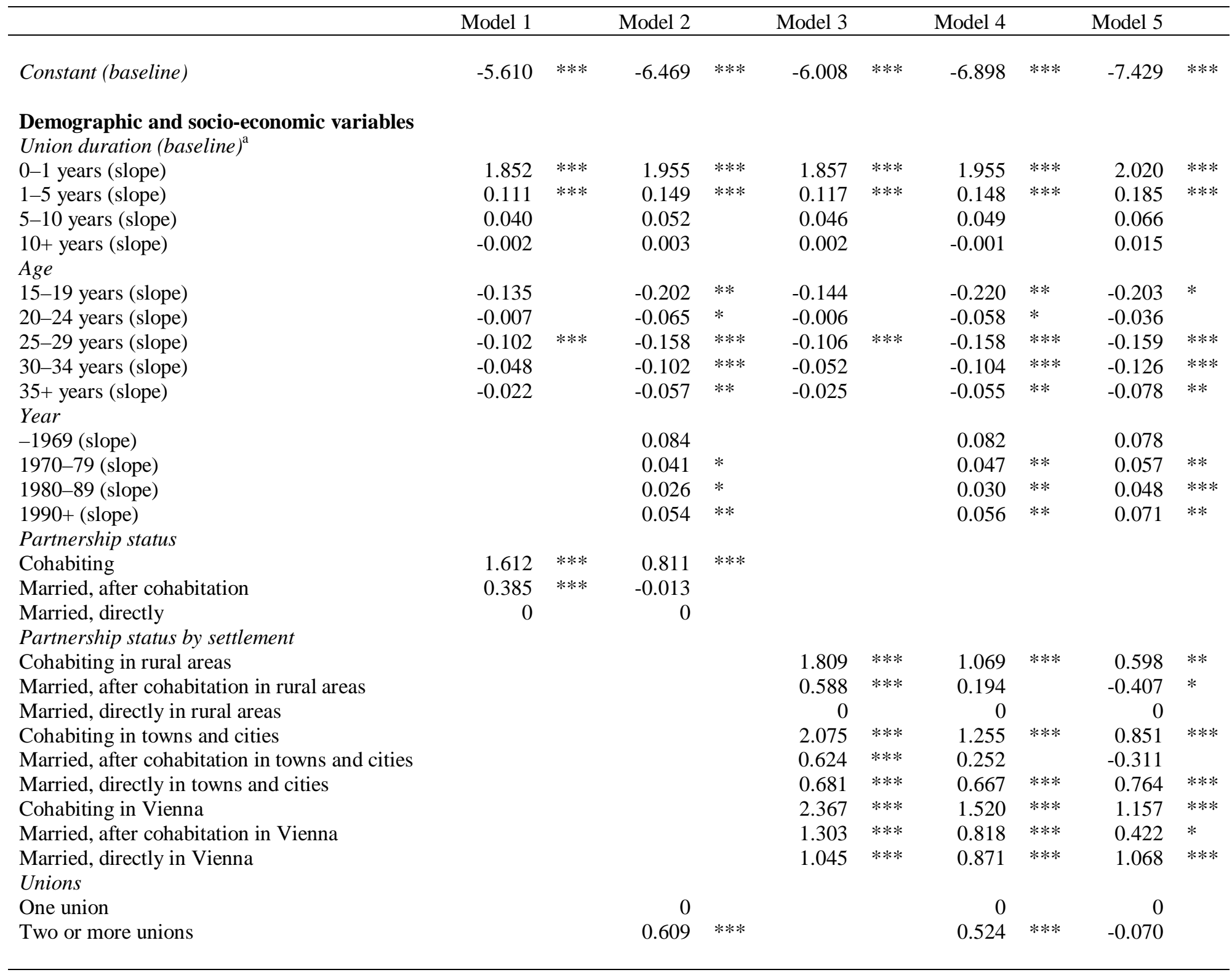


Time since first / last conception ${ }^{\mathrm{ab}}$

$0-0.75$ years (slope)

$0.75-2.75$ years (slope)

$2.75+$ years (slope)

$.268 * * *$

$0.602 * * *$

0.017

$-1.226 * * *$

Children

One child

Two or more children

0

Stepchildren

No stepchildren

$0.436 * * *$

One or more stepchildren

Educational level

0.120

0.609

$-1.153 * * *$

Basic

Secondary

Higher

0

$-0.186$

0.018

0.581

0

Educational enrollment

Not enrolled

Enrolled

$-0.384$

$-0.373$

0

Religiousness

No

Yes

0
0.301

0

\section{Parental home}

Parental divorce

No

Yes

0

$0.481 * *$

0

0.164

0.155

\section{Woman's independence}

Comparative education

Man better educated

No difference

Woman better educated

Employment status

Not employed

Employed

Employment status (at start of union)

Man employed, woman employed

Man employed, woman not employed

Man not employed, woman employed

Man not employed, woman not employed

0.060

$0.897 * * *$

0

$0.382 * * *$

0
-0.017

$-0.063$

0.397
0

$\begin{array}{rr}0 & 0\end{array}$

$-0.443$

$\begin{array}{rr}0 & 0 \\ 0.252 & 0.261\end{array}$

.261

$\begin{array}{rrr}0 & & 0 \\ -0.335 & * * * & -0.491\end{array} * * *$

$0.446 * * * \quad 0.579 \quad * *$

$-0.003-0.025$

$0 \quad 0$

$0.889 * * * \quad 0.993 * * *$

0

$0.363 * * * \quad 0.425 * * *$

$\begin{array}{rr}0 & 0 \\ 0.035 & 0.042\end{array}$

$-0.021-0.035$

$0.420 * * \quad 0.481 * *$ 
Relative ages of partners

Man younger

No difference

Man older

$0.319 * *$

$-0.118$

$0.327 * *$

0

0.107

$.388 * *$

Place of residence, migration and mobility

Migrations

No migrations

One migration

Frequency of migrations

One migration

Two or more migrations

Residential moves

No moves

One move

Frequency of residential moves

One move

Two or more moves

$-0.016$

0.031

$0.963 * * *$

$-0.212 * *$

$0.597 * *$

Standard deviation of residuals

Cohabitation

Direct marriage

Union dissolution

Correlation between the residuals

Cohabitation - marriage

Cohabitation-dissolution

Marriage-dissolution

Sum of log-likelihoods

Significance: '*'=10\%; '**'=5\%; '***'=1\%

n.e. - not estimated.

a - For linear splines we present slope estimates which show how the hazard increases or decreases over a certain time period. For example, during the pregnancy (see time since conception) the log-risk of dissolution decreases by -1.153 per year (model 5), reaching a level of $-0.865(0.75 \times(-1.153)$ ) by the time of birth. In

relative terms, the risk is then $58 \%$ lower than prior to conception $((\exp (-0.865)-1) \times 100 \%)$. The log-hazard of union dissolution increases 0.581 per year during the first two years of the child's life, reaching a level of $0.297(-0.865+(0.581 \times(2.75-0.75)))$ when the child is two, which is a $35 \%$ higher risk than prior to conception $((\exp (0.297)-1) \times 100 \%)$

$\mathrm{b}$ - The reference category for the first conception is parity zero.

${ }^{c}$ - The sum of log-likelihoods relates to the union dissolution and union formation equations estimated separately (models 1 to 4 ) or simultaneously (model 5). As our research focus is on union dissolution, we have only reported the sum of log-likelihoods, and not the parameter estimates for the union formation equations. 
Figure 1 Research model

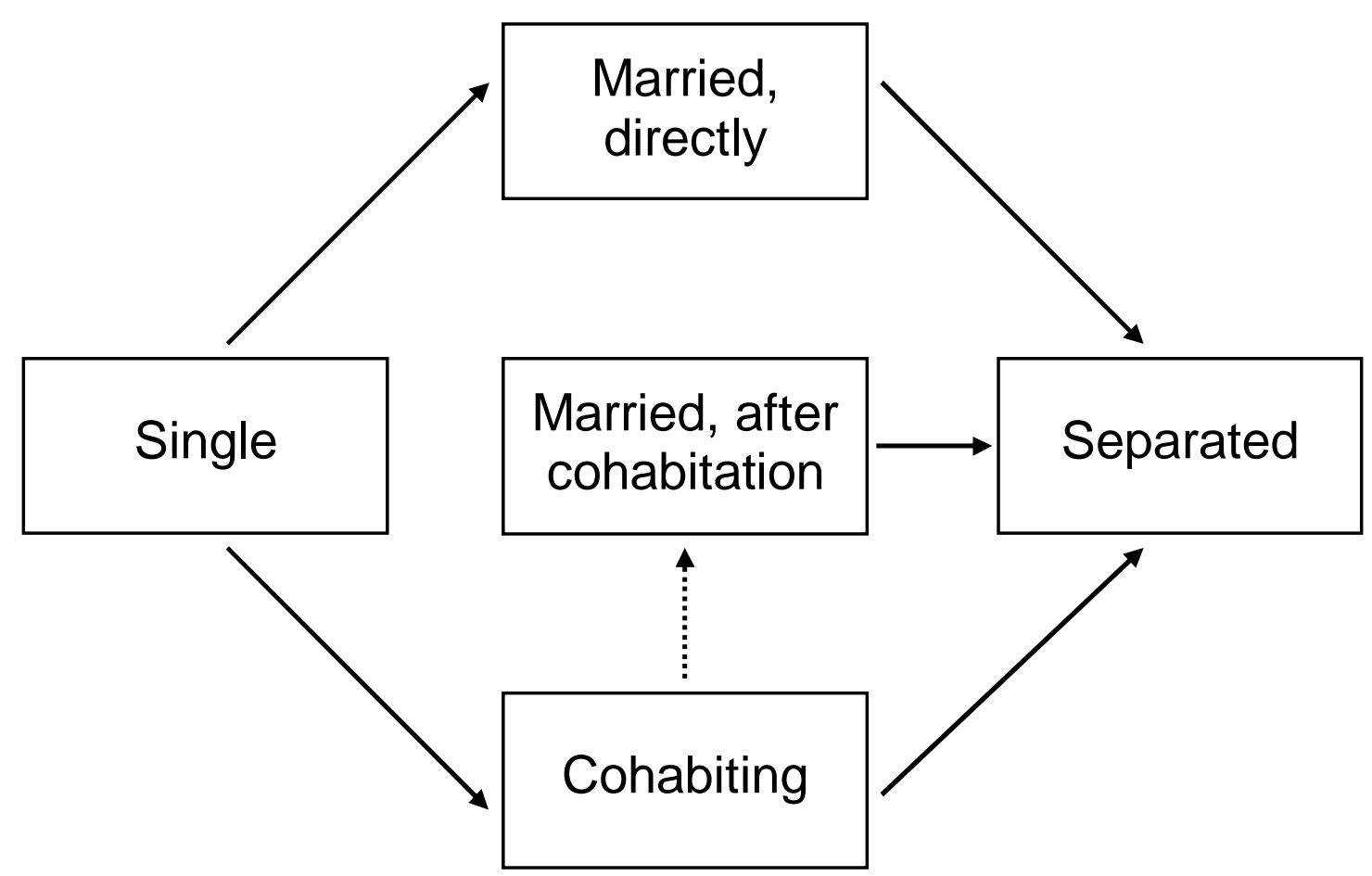

Note: The solid arrows indicate the processes that were explicitly modelled in the simultaneous equations framework. 
Figure 2 Relative risk of union dissolution by partnership status (controlling for union duration and age)

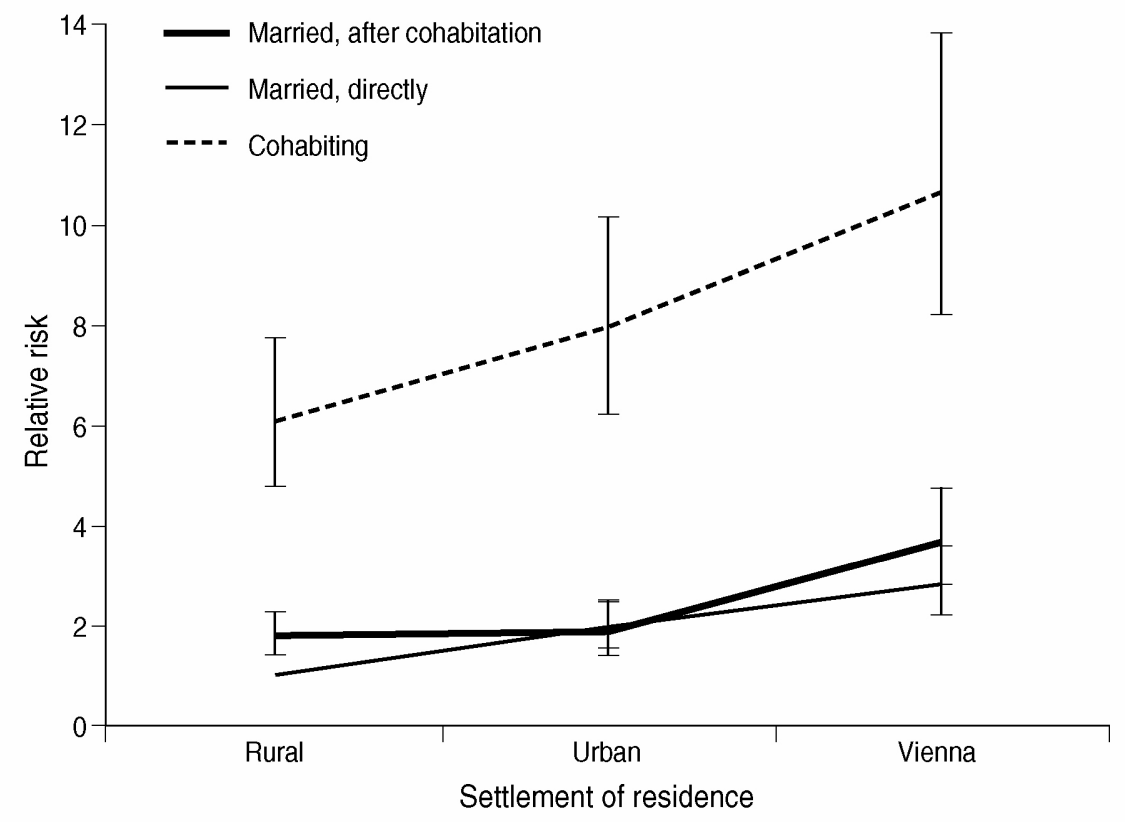

Figure 3 Relative risk of union dissolution by partnership status (controlling for all demographic and socio-economic variables)

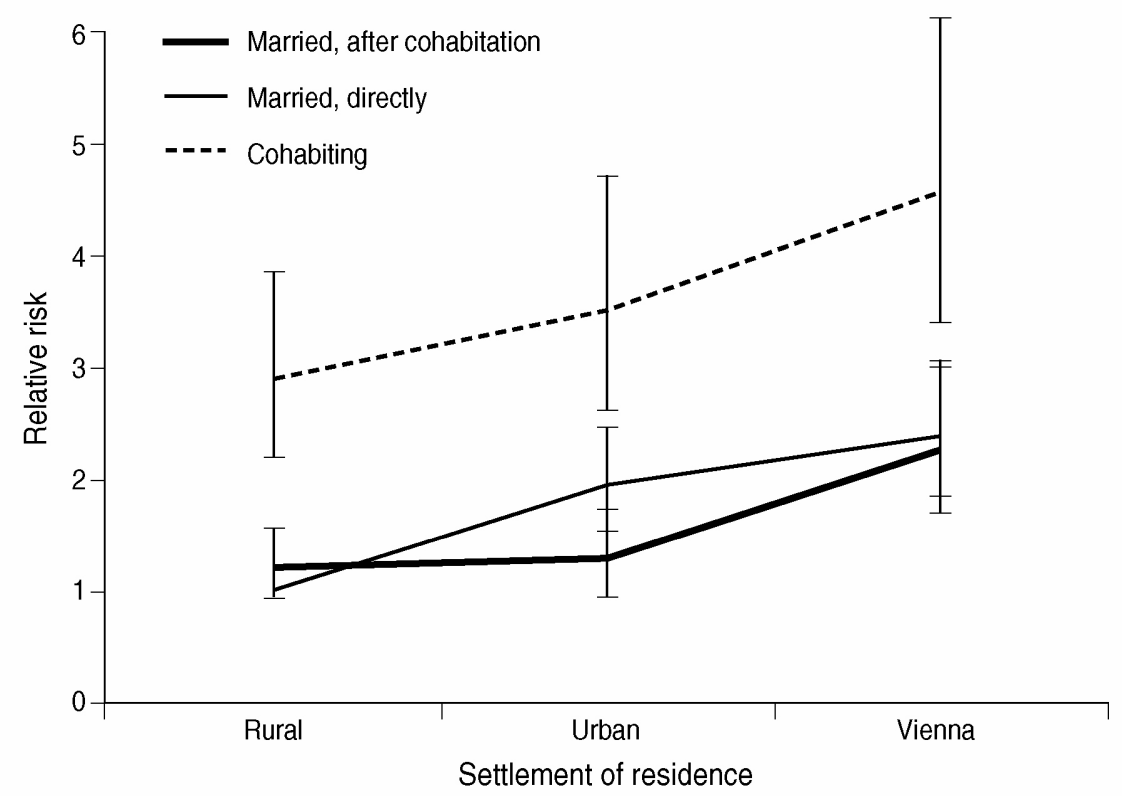


Figure 4 Relative risk of union dissolution by partnership status (controlling for all demographic and socio-economic variables, heterogeneity and selection)

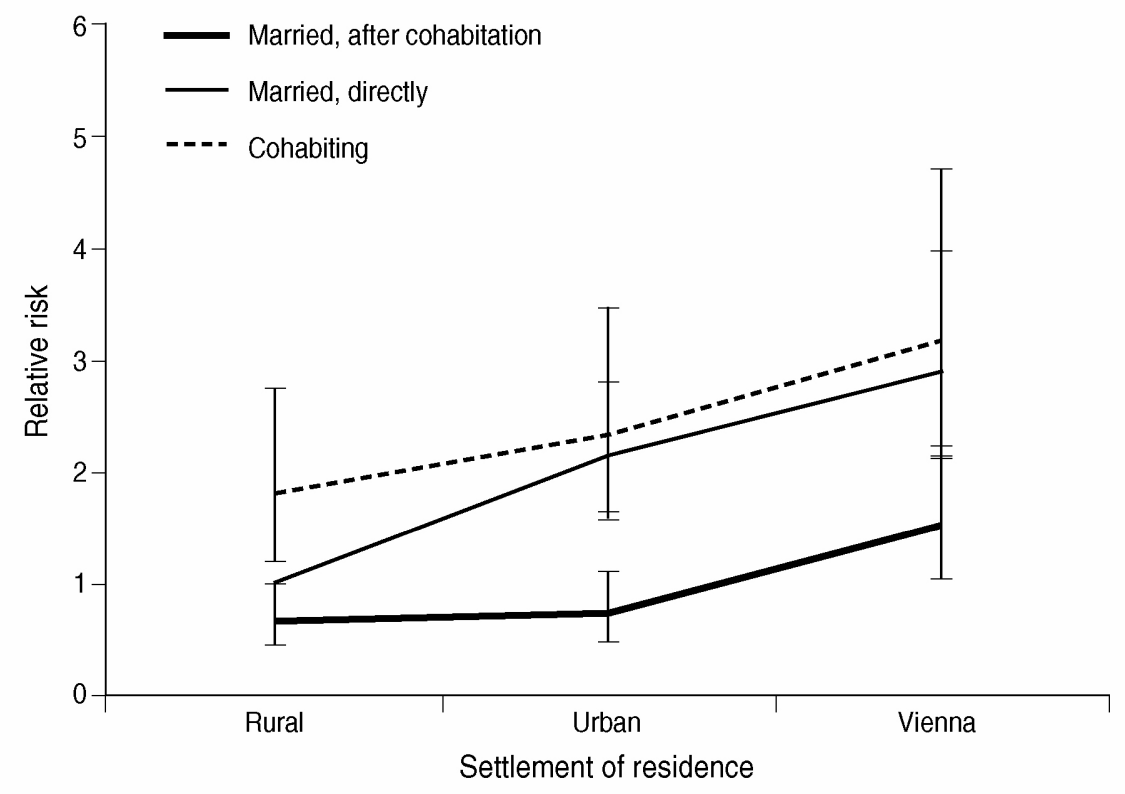

